\title{
Suplementos múltiplos para novilhas de corte a pasto no período seco: características nutricionais
}

\section{Multiple supplements for beef heifers on pasture during the dry season: nutritional characteristics}

\author{
Renata Pereira da Silva-Marques ${ }^{1 *}$; Joanis Tilemahos Zervoudakis'; \\ Luciana Keiko Hatamoto-Zervoudakis ${ }^{2}$; Luciano da Silva Cabral'; \\ Emerson Alexandrino ${ }^{3}$; Antônio José Neto ${ }^{4}$; Juliane Quenoizoré Soares ${ }^{5}$; \\ Alan Carlos Barboza Melo ${ }^{6}$
}

\begin{abstract}
Resumo
Objetivou-se avaliar níveis de suplementos múltiplos para novilhas de corte em baixa oferta de pasto, sobre consumo e digestibilidade dos nutrientes, $\mathrm{pH}$ e concentração de nitrogênio amoniacal ruminal, balanço de nitrogênio e síntese e eficiência microbiana. Foram utilizadas cinco novilhas Nelore com peso corporal médio inicial de $344,00 \pm 21,10 \mathrm{~kg}$ e idade média inicial de 22 meses. Foram avaliados os seguintes suplementos: controle (SAL) e níveis de suplementação de 2, 4, 6 e $8 \mathrm{~kg} / \mathrm{animal} / \mathrm{dia}$, perfazendo as seguintes proporções em porcentagem do peso corporal médio (PCM): 0,55; 1,11; 1,66 e $2,22 \%$ PCM, respectivamente. O delineamento foi em quadrado latino com cinco suplementos e cinco repetições. Os consumos de matéria seca total, proteína bruta (PB) e nutrientes digestíveis totais, e as digestibilidades aparente total da matéria seca, $\mathrm{PB}$, carboidratos totais e não fibrosos aumentaram linearmente $(\mathrm{P}<0,0001)$ e o consumo de matéria seca de forragem reduziu $(\mathrm{P}<0,0001)$ com os níveis de suplementação. As estratégias de suplementação promoveram redução sobre o $\mathrm{pH}$ ruminal $(\mathrm{P}=0,0343) \mathrm{e}$ aumento na concentração de nitrogênio amoniacal ruminal $\left(\mathrm{N}_{-} \mathrm{NH}_{3}\right)(\mathrm{P}=0,0004)$ antes do fornecimento de suplementos, e após, este $\mathrm{N}-\mathrm{NH}_{3}$ apresentou comportamento quadrático $(\mathrm{P}=0,0023)$. A ingestão de nitrogênio, excreção de ureia na urina e excreção de nitrogênio nas fezes aumentaram linearmente $(\mathrm{P}<0,0001)$ em função dos níveis de suplementação. $\mathrm{O}$ fornecimento de elevados níveis de suplemento múltiplo reduz o consumo de forragem e apresenta-se como alternativa para bovinos mantidos em sistema com baixa oferta de pasto no período seco.

Palavras-chave: Coprodutos, Brachiaria brizantha, efeito substitutivo, rúmen, suplementação
\end{abstract}

\footnotetext{
Abstract

The objective was to evaluate levels of multiple supplements supplied to beef heifers in low supply of pasture on intake and nutrients digestibility, $\mathrm{pH}$ and concentration of ruminal ammonia nitrogen, nitrogen balance, synthesis and microbial efficiency. Five Nellore heifers with initial body weight of

${ }^{1}$ Discente de Doutorado em Ciência Animal, Universidade Federal de Mato Grosso, UFMT, Cuiabá, MT. E-mail: renatinharps@, hotmail.com

2 Profs. Drs., UFMT, Cuiabá, MT. E-mail: joanis@ufmt.br; lukeiko@yahoo.com.br; cabralls@ufmt.br

${ }^{3}$ Prof. Dr., Universidade Federal do Tocantins, UFT, Araguaína, TO. E-mail: e alexandrino@yahoo.com.br

${ }^{4}$ Discente de Doutorado em Zootecnia, Universidade Estadual Paulista, UNESP, Jaboticabal, SP. E-mail: antoniojoseneto@yahoo. com.br

5 Discente de Mestrado em Ciência Animal, UFMT, Cuiabá, MT. E-mail: juliane_qs@hotmail.com

${ }^{6}$ Discente de Zootecnia, UFMT, Cuiabá, MT. E-mail: allan.a.b@hotmail.com

* Autor para correspondência
} 
$344.00 \pm 21.10 \mathrm{~kg}$ and average initial age of 22 months were used. The following supplements were evaluated as fed to the animals: control (mineral supplement) and supplementation levels of 2, 4, 6 and 8 $\mathrm{kg} / \mathrm{animal} /$ day, composing the following percentages of body weight (BW): $0.55,1.11,1.66$ and $2.22 \%$, respectively. The experimental design was a Latin square with five replications and five supplements. Intakes of total dry matter, crude protein $(\mathrm{CP})$ and total digestible nutrients, and total apparent digestibility of dry matter, crude protein, total carbohydrates and no fiber carbohydrates increased linearly $(\mathrm{P}<0.0001)$ and dry matter intake of forage decreased $(\mathrm{P}<0.0001)$ with supplementation levels. Supplementation strategies promoted reduction on ruminal $\mathrm{pH}(\mathrm{P}=0.0343)$ and increased concentration of ruminal ammonia nitrogen $\left(\mathrm{NH}_{3}-\mathrm{N}\right)(\mathrm{P}=0.0004)$ before the supply of supplements, and after, this $\mathrm{NH}_{3}-\mathrm{N}$ presented quadratic behavior $(\mathrm{P}=0.0023)$. Nitrogen intake, excretion of urea in urine and nitrogen excretion in feces increased linearly $(\mathrm{P}<0.0001)$ according to supplementation levels. The supply of high levels of multiple supplements reduces forage intake and presents itself as an alternative to cattle maintained in a systems with low supply of pasture in the dry season.

Key words: Coproducts, Brachiaria brizantha, substitutive effect, rumen, supplementation

\section{Introdução}

A bovinocultura de corte no Brasil tem sido desafiada a estabelecer sistemas de produção que sejam capazes de produzir de forma eficiente e sustentável, carne de boa qualidade a baixo preço. Esta atividade se destaca pela competitividade econômica, pois a maioria do rebanho se alimenta basicamente de gramíneas forrageiras (MORAES et al., 2006).

Deste modo, o uso eficiente das forragens possibilita a redução dos custos de produção, variável esta, de maior impacto econômico nos sistemas de produção. Segundo Van Soest (1994) o grande desafio para os nutricionistas que trabalham com ruminantes é o de melhorar a utilização de forragens, de modo que estes animais possam explorar seu verdadeiro potencial genético.

No entanto, a produtividade e qualidade dessas gramíneas sofrem variações sazonais ao longo do ano devido às condições climáticas, permitindo desempenho inconstante dos animais ao longo do ano, resultando em baixos índices zootécnicos (PAULINO; DETMANN; VALADARES FILHO, 2008). No período seco do ano o rebanho bovino alimenta-se de forragem de baixo valor nutritivo, caracterizada por elevado teor de fibra indigestível e teores de proteína bruta (PB) inferiores ao nível crítico (7\% PB na dieta basal) (VAN SOEST, 1994).
Os bovinos necessitam no mínimo de 6-7\% de PB na dieta, para que não haja comprometimento da fermentação ruminal, uma vez que, teores abaixo deste nível prejudicam a reciclagem de nitrogênio via saliva, não satisfazendo os requisitos de nitrogênio dos microrganismos (VAN SOEST, 1994). Bovinos ingerindo forragens com teor de PB inferior a este limite, não são capazes de manter o nível mínimo de $10 \mathrm{mg} / \mathrm{dL}$ de nitrogênio amoniacal $\left(\mathrm{N}_{-} \mathrm{NH}_{3}\right)$ necessário para manter o crescimento das bactérias celulolíticas (LENG, 1990), reduzindo assim a atividade dos microrganismos do rúmen e, em consequência, há decréscimo nas taxas de digestão e passagem do alimento, prejudicando o consumo voluntário e a digestibilidade dos nutrientes (VAN SOEST, 1994).

Diante disso, podem ser adotadas estratégias como a utilização de confinamento ou fornecimento de suplementos concentrados de médio/alto consumo, que permitam atender inicialmente os requisitos nutricionais da microbiota ruminal e, adiante, dos ruminantes propriamente ditos. O conhecimento do ambiente ruminal para permitir condições favoráveis ao crescimento dos microrganismos é fundamental para que os animais ruminantes utilizem eficientemente os carboidratos fibrosos da forragem ingerida. Sendo assim, a determinação quantitativa dos processos de fermentação requer mensurações da concentração de nitrogênio amoniacal $\left(\mathrm{N}-\mathrm{NH}_{3}\right)$, variações do $\mathrm{pH}$ 
e outras mensurações que refletem a atividade da microflora (REIS et al., 2005).

A adoção dessas estratégias de suplementação é essencial para manutenção de níveis produtivos mínimos em sistemas de pastejo de não equilíbrio, ou seja, sistemas com grandes variações produtivas de forragens, decorrentes das limitações físicoquímicas dos solos (PAULINO et al., 2004). Sendo assim, propõe-se o uso de suplementos de custo reduzido, o que pode ser adquirido pela substituição de ingredientes tradicionais (milho e farelo de soja) por coprodutos da agroindústria (casca de café, casca de soja, bagaço de cana de açúcar, feno de feijão gandu), que serão utilizados em maior proporção em sua formulação, "flexibilizando" maiores níveis de suplementação, com maior rentabilidade econômica do sistema (ZERVOUDAKIS et al., 2011).
Deste modo, objetivou-se avaliar algumas características nutricionais em novilhas de corte em pastejo suplementadas com diferentes níveis de fornecimento de suplementos múltiplos em sistemas com baixa oferta de forragem no período de seca.

\section{Material e Métodos}

O experimento foi conduzido no setor de Bovinocultura de Corte, da Fazenda Experimental da Faculdade de Agronomia, Medicina Veterinária e Zootecnia - FAMEVZ da Universidade Federal de Mato Grosso - UFMT, no período da seca, entre os meses de agosto a novembro. O clima da região é do tipo Aw de acordo com a classificação Köppen, ou seja, clima tropical, megatérmico, com inverno seco e chuvas no verão (Tabela 1).

Tabela 1. Valores médios das temperaturas máximas e mínimas, umidade relativa do ar e precipitação pluviométrica, coletadas durante o período experimental.

\begin{tabular}{|c|c|c|c|c|}
\hline \multirow{2}{*}{ Mês } & \multicolumn{2}{|c|}{ Temperatura média $\left({ }^{\circ} \mathrm{C}\right)$} & \multirow{2}{*}{$\begin{array}{c}\text { Umidade Relativa } \\
\text { do ar (\%) }\end{array}$} & \multirow{2}{*}{ Precipitação (mm) } \\
\hline & Máxima & Mínima & & \\
\hline Agosto & 35,8 & 15,0 & 54,5 & 0,0 \\
\hline Setembro & 35,8 & 20,9 & 50,0 & 9,5 \\
\hline Outubro & 35,1 & 21,7 & 64,5 & 73,2 \\
\hline Novembro & 33,1 & 19,8 & 74,7 & 184,4 \\
\hline
\end{tabular}

Fonte: Estação Agrometeorológica Padre Ricardo Remetter - Fazenda Experimental UFMT.

Foram utilizadas cinco novilhas Nelores, com idade e pesos médios iniciais de 22 meses e 344,00 $\mathrm{kg}$, respectivamente, destinadas individualmente a cinco piquetes de 0,24 ha cada, formados com gramínea Brachiaria brizantha cv. Marandu, contendo bebedouro e comedouro coberto. Paralelamente aos piquetes, situava-se o curral de manejo, no qual foram realizadas as coletas nos animais. Ao início do experimento, todos os animais foram submetidos ao controle de endo e ectoparasitas.

O experimento foi conduzido em delineamento em quadrado latino $5 \times 5$, com cinco animais e cinco suplementos. Foram avaliados suplementos múltiplos e mistura mineral (Tabela 2), com fornecimento de 2; $4 ; 6$ e $8 \mathrm{~kg} / \mathrm{dia}$, perfazendo níveis de fornecimento de: 0,$55 ; 1,11 ; 1,66$ e $2,22 \%$ do peso corporal médio (PCM) das novilhas que receberam suplementação múltipla, respectivamente, calculados de acordo com as exigências propostas para fêmeas Nelore em confinamento, adotando PCM de $360 \mathrm{~kg}$ e almejando-se ganho médio diário (GMD) de $500 \mathrm{~g} / \mathrm{animal} /$ dia (VALADARES FILHO; PAULINO; MAGALHÃES, 2006). Foram coletadas amostras dos suplementos utilizados durante o preparo das misturas, para posteriores análises laboratoriais. 
A variação na composição dos suplementos foi decorrente da fixação no consumo de uréia (90g/animal dia para todos os suplementos) e da inclusão de aproximadamente $50 \%$ de casca de soja (Tabela 2), que pelo seu elevado teor em fibra potencialmente digestível, foi utilizada como fonte volumosa com intuito de substituir a fração volumosa da dieta dos animais, uma vez que nos piquetes havia limitada oferta de matéria seca de forragem.

Tabela 2. Composição alimentar do concentrado fornecido aos animais.

\begin{tabular}{lccccc}
\hline \multirow{2}{*}{ Ingredientes } & \multirow{2}{*}{$\mathrm{SM}^{1}$} & \multicolumn{4}{c}{ Suplementos $^{2}$} \\
\cline { 3 - 6 } & & 2 & 4 & 6 & 8 \\
\hline Casca soja & - & 500,0 & 500,0 & 540,0 & 560,0 \\
Milho grão triturado & - & 160,0 & 170,0 & 150,0 & 160,0 \\
Farelo de girassol & - & 100,0 & 100,0 & 100,0 & 103,7 \\
Farelo soja & - & 145,0 & 177,5 & 175,0 & 150,0 \\
Uréia: Sulfato de Amônia $^{9: 1}$ & - & 45,0 & 22,5 & 15,0 & 11,3 \\
Mistura mineral $^{1}$ & 1000,0 & 50,0 & 30,0 & 20,0 & 15,0 \\
\hline Total & 1000,0 & 1000,0 & 1000,0 & 1000,0 & 1000,0 \\
\hline
\end{tabular}

${ }^{1} \mathrm{SM}$ - Suplemento mineral comercial: Níveis de garantia: cálcio $198 \mathrm{~g}$; fósforo $87 \mathrm{~g}$; sódio 97,6g; magnésio 5,1g; enxofre $12 \mathrm{~g}$; iodo $17,7 \mathrm{mg}$; ferro $280 \mathrm{mg}$; selênio $18 \mathrm{mg}$; cobalto $80 \mathrm{mg}$; manganês $527 \mathrm{mg}$; flúor $870 \mathrm{mg}$; cobre $1.250 \mathrm{mg}$ e zinco $3.500 \mathrm{mg} . \%$

${ }^{2}$ Níveis de fornecimento de suplementos de 0,$55 ; 1,11 ; 1,66$ e $2,22 \%$ do peso corporal para $2,4,6$ e $8 \mathrm{~kg} / \mathrm{animal} /$ dia, respectivamente, ( $\mathrm{g} / \mathrm{kg}$ de matéria natural).

Fonte: Elaboração dos autores.

Os suplementos foram fornecidos diariamente em dois horários fixos: $50 \%$ da quantidade diária a ser fornecida às dez horas da manhã e $50 \%$ às três horas da tarde.

O experimento foi composto por cinco períodos de avaliação nutricional de 20 dias de duração cada, correspondendo a um período experimental total de 100 dias. Os primeiros nove dias de cada período foram destinados à adaptação dos animais ao suplemento (no $1^{\circ}$ e $2^{\circ}$ dia todos os animais receberam $2 \mathrm{~kg}$ de suplemento, do $3^{\circ}$ ao $5^{\circ}$ dia os animais do suplemento 4,6 e $8 \mathrm{~kg}$ receberam $4 \mathrm{~kg} /$ dia, no $7^{\circ}$ e $8^{\circ}$ as novilhas do suplemento 6 e $8 \mathrm{~kg}$ receberam $6 \mathrm{~kg} / \mathrm{dia}$ e do $9^{\circ}$ dia em diante os animais do suplemento 8 receberam $8 \mathrm{~kg}$ de suplemento) e os onze dias restantes para a realização das coletas. A cada final de período, durante a avaliação nutricional, as novilhas foram pesadas, sem jejum, para acompanhamento do desempenho e do consumo em função do peso corporal.
Para estimar a massa de forragem e matéria seca potencialmente digestível (MSpD), foram realizadas coletas de amostras de forragem nos diferentes piquetes no primeiro dia de cada período experimental, através do corte da forragem a $5 \mathrm{~cm}$ do solo, de três áreas delimitadas por um quadrado metálico de 0,5 x 0,5 m, escolhidos na altura média do dossel forrageiro de cada piquete (25 pontos em cada diagonal, totalizando 50 pontos de altura mensurados por piquete), conforme recomendações do Instituto Nacional de Ciência e Tecnologia Ciência Animal (INCT - CA).

Após a coleta, as amostras de forragem de cada piquete foram pesadas e homogeneizadas, e a partir dessas retiradas duas alíquotas: uma para avaliação da matéria seca de forragem/hectare e a outra para fracionamento dos componentes estruturais da planta, e posterior, análise das disponibilidades por hectare de matéria seca de lâmina foliar verde, lâmina foliar seca, pseudocolmo verde e 
pseudocolmo seco. A amostragem da forragem consumida pelos animais foi obtida via simulação manual do pastejo. As amostras de forragem foram imediatamente pesadas após as coletas e congeladas a $-20^{\circ} \mathrm{C}$. Posteriormente foram descongeladas e secas em estufa de ventilação forçada a $65^{\circ} \mathrm{C}$, moídas em moinho tipo Willey (com peneira de malha de 1,0 $\mathrm{mm}$ ), armazenadas por período, em frascos de plásticos com tampa, devidamente identificados, para posterior analises químico-bromatológicas no Laboratório de Nutrição Animal da Faculdade de Agronomia, Medicina Veterinária e Zootecnia da Universidade Federal de Mato Grosso (FAMEV UFMT).

Das amostras destinadas à estimativa da massa de forragem, foi determinado o resíduo insolúvel em detergente neutro avaliado após incubação in situ das amostras por 240 horas (FDNi) (CASALI et al., 2008), para cálculo do percentual de MS potencialmente digestível (MSpD) disponível aos animais, segundo equação proposta por Paulino, Detmann e Valadares Filho (2006):

\section{MSpD = 0,98 x (100- FDN $)+($ FDN-FDNi $)$}

em que: $0,98=$ coeficiente de digestibilidade verdadeiro do conteúdo celular; FDN = fibra em detergente neutro; FDNi $=$ FDN indigestível.

As amostras dos ingredientes, suplementos, forragens e das fezes foram analisadas para determinação dos teores de matéria seca (MS), matéria mineral (MM), matéria orgânica (MO), proteína bruta $(\mathrm{PB})$ e extrato etéreo (EE) de acordo com Silva e Queiroz (2002). As avaliações da fibra em detergente neutro (FDN), fibra em detergente neutro corrigida para cinzas e proteína (FDNcp), fibra em detergente ácido (FDA) foram realizadas conforme o protocolo descrito por Van Soest, Robertson e Lewis (1991).

Os carboidratos totais (CT) das amostras foram calculados segundo metodologia descrita por Sniffen et al. (1992), em que CT $(\%)=100-(\% \mathrm{~PB}+\% \mathrm{EE}$ + \%Cinzas). A quantificação dos carboidratos não fibrosos (CNF) dos suplementos foi realizada de acordo com adaptação de Hall (2000), em virtude da inclusão de uréia na composição dos suplementos:

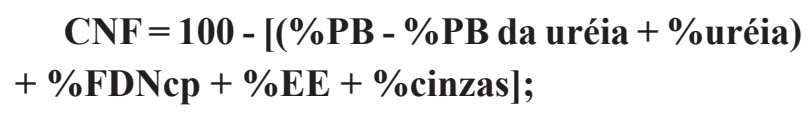

onde: FDNcp = fibra em detergente neutro corrigida para cinzas e proteína.

Os teores de nutrientes digestíveis totais (NDT) foram estimados segundo o NRC (2001) com base na composição químico-bromatológica dos alimentos, por intermédio da equação: NDT $(\%)=$ $(\mathrm{PBD}+\mathrm{CNFD}+\mathrm{FDNpD}+\mathrm{EED} \times 2,25)-7$, onde a constante 7 refere-se ao valor metabólico fecal.

Os valores de proteína bruta digestível (PBD), ácidos graxos digestíveis (AGD), fibra em detergente neutro corrigida para proteína digestível (FDNpD) e carboidratos não fibrosos digestíveis (CNFD) foram estimados de acordo com as seguintes equações (NRC, 2001):

PBD $($ volumosos $)=$ PB $\times$ EXP(-1,2 $\times$ PIDA/PB $)$;

PBD $($ concentrados $)=$ PB x [1- $(0,4 \times$ PIDA/PB $)$;

$\mathrm{EED}=(\mathrm{EE}-1)$

$\mathrm{CNFD}=(0,98 \times \mathrm{CNF} \times \mathrm{PAF})$;

$\mathrm{FDNpD}=0,75 \times(\mathrm{FDNp}-\mathrm{L}) \times\left[1-(\mathrm{L} / \mathrm{FDNp})^{0,667}\right]$.

Em que: PIDA - proteína insolúvel em detergente ácido; PAF - fator de ajuste para processamento físico; L - lignina; FDNp - FDN corrigida para proteína.

Para estimar a excreção fecal foram fornecidos para cada novilha diariamente $10 \mathrm{~g}$ do indicador externo óxido de cromo $\left(\mathrm{Cr}_{2} \mathrm{O}_{3}\right)$ acondicionado em cartucho de papel e introduzido diretamente no esôfago dos animais às 11 horas, com o auxílio de um aplicador de PVC, entre o décimo e o décimo sexto dia de cada período experimental. As amostras de fezes foram coletadas diretamente do reto dos animais no décimo quinto dia (16 horas), décimo sexto dia (12 horas) e décimo sétimo dia (08 horas), acondicionadas em sacos 
plásticos etiquetados e posteriormente congeladas a $-20^{\circ} \mathrm{C}$. Em seguida foram secas por 72 horas em estufa de ventilação forçada $\left(65^{\circ} \mathrm{C}\right)$ e moídas em moinho de facas tipo Willey equipado com peneira com malha de 1,0 mm. As amostras referentes aos diferentes horários de coleta formaram uma amostra composta, constituída com base no peso seco para cada animal.

A excreção de matéria seca fecal foi estimada (g/dia) pela relação entre a quantidade fornecida do indicador ( $\mathrm{g}$ ) e sua concentração nas fezes ( $\mathrm{g} /$ kg), segundo Burns, Pond e Fisher (1994). Para obtenção de estimativas do consumo voluntário de matéria seca (CMS), utilizou-se a fibra em detergente neutro indigestível (FDNi) como indicador interno. Para isso, amostras de forragem, obtidas por simulação do pastejo, suplementos e de fezes foram incubadas no rúmen por meio de sacos de tecido não tecido (TNT) durante 240 horas, conforme metodologia sugerida por Casali et al. (2008). Para estimativas do consumo voluntário de MS dos animais foi utilizada a equação proposta por Detmann et al. (2001):

\section{CMS $=\{[($ EF x CIF $)-$ IS $] /$ CIFO $\}+$ CMSS;}

em que: $\mathrm{CMS}=$ consumo de matéria seca; EF $=$ excreção fecal $(\mathrm{kg} /$ dia $) ; \mathrm{CIF}=$ concentração do indicador (FDNi) nas fezes $(\mathrm{g} / \mathrm{kg})$; IS = indicador (FDNi) presente no suplemento ( $\mathrm{kg} / \mathrm{dia})$; CIFO = concentração do indicador (FDNi) na forragem $(\mathrm{g} / \mathrm{kg})$; CMSS = consumo de matéria seca de suplemento $(\mathrm{kg})$.

Para relacionar o consumo ao PC dos animais, foi utilizado como referência, o peso médio no período, estimado pela média entre os valores inicial e final de cada período.

Com a finalidade de se estimar as excreções diárias de urina e uréia e concentrações plasmáticas de uréia, foram coletadas no $18^{\circ}$ dia, duas horas antes (8h) da suplementação da manhã (10h) e duas horas após (17h) o fornecimento do suplemento da tarde (15h), amostras "spot" de urina em micção espontânea e de sangue através de punção da veia coccígea. Após a coleta de urina, foram feitas duas amostras: uma em que $10 \mathrm{~mL}$ de urina foram diluídas em $40 \mathrm{~mL}$ de $\mathrm{H}_{2} \mathrm{SO}_{4}(0,036 \mathrm{~N})$ para posteriores análises de alantoína, ácido úrico e uréia e outra de $50 \mathrm{~mL}$ de urina pura para análises de creatinina, ambas armazenadas em tubos falcon e congeladas a $-20^{\circ} \mathrm{C}$. As amostras de sangue foram centrifugadas a $4000 \mathrm{rpm}$ por 15 minutos e o soro sanguíneo armazenado em eppendorf's identificados e congelados para posterior determinação dos teores de uréia (VALADARES; BRODERICK; VALADARES FILHO, 1999).

Para determinação do $\mathrm{pH}$ e da concentração de amônia no líquido ruminal, as amostras foram coletadas via sonda esofágica no $19^{\circ} \mathrm{e}$ $20^{\circ}$ dia de cada período, duas horas antes da suplementação (10h - tempo 0h) e duas horas após o fornecimento de suplemento no período da tarde (15h- tempo 2h). Para esta coleta foi utilizada uma mangueira acoplada a uma ponta de aço inoxidável perfurada em forma de peneira e uma bomba manual de sucção. As leituras de $\mathrm{pH}$ foram feitas imediatamente após a coleta, por intermédio de potenciômetro digital. Para a determinação de amônia foi separada uma alíquota de $50 \mathrm{~mL}$ de líquido ruminal filtrada em gaze, à qual adicionouse $1 \mathrm{~mL}$ de ácido sulfúrico $1: 1$, acondicionada em tubo falcon, identificada e congelada a $-20^{\circ} \mathrm{C}$ para posterior análise laboratorial. As concentrações de $\mathrm{N}-\mathrm{NH}_{3}$ do líquido ruminal foram determinados pelo sistema micro-Kjeldahl, sem digestão ácida da amostra, mediante destilação com hidróxido de potássio $(\mathrm{KOH}) 2 \mathrm{~N}$, conforme técnica descrita por Preston (1995).

$\mathrm{Na}$ urina foram estimadas as concentrações de uréia, creatinina e ácido úrico e no soro sanguíneo a concentração de uréia utilizando-se kits comerciais (Labtest $\left.{ }^{\circledR}\right)$. As análises de alantoína na urina foram feitas pelo método colorimétrico, 
conforme Fujihara et al. (1987), modificada por Chen e Gomes (1992). A conversão dos valores de uréia em nitrogênio uréico foi realizada pela multiplicação dos valores obtidos pelo fator 0,466 .

O volume urinário diário foi calculado com base na relação entre a excreção diária de creatinina (EC) e o peso corporal (PC), e a sua concentração nas amostras spot adotando como referência a equação proposta por Chizzotti et al. (2008): EC (mg/kg PC) $=32,27-0,01093 \times$ PC.

Sendo assim, a excreção urinária diária de compostos nitrogenados foi o produto entre sua concentração nas amostras spot e o valor estimado de volume urinário. A excreção total de derivados de purina foi calculada pela soma das quantidades de alantoína e ácido úrico excretados na urina. As purinas absorvidas (Y, mmol/dia) foram calculadas a partir da excreção de derivados de purinas (X, mmol/dia), segundo Verbic et al. (1990) por intermédio da equação: $\mathrm{Y}=\left(\mathrm{X}-0,385 \mathrm{PC}^{0,75}\right) / 0,85$ em que: $0,385 \mathrm{PC}^{0,75}=$ contribuição endógena para a excreção de purinas e 0,85 = recuperação de purinas absorvidas como derivados de purinas.

A síntese ruminal de compostos nitrogenados (Y, g Nmic/dia), foi calculada em função das purinas absorvidas (X, mmol/dia), utilizando-se a equação descrita por Chen e Gomes (1992) e modificada por Valadares, Broderick e Valadares Filho (1999): $\mathrm{Y}=$ $70 \mathrm{X} / 0,83 \times 0,134 \times 1000$ em que: $70=$ conteúdo de $\mathrm{N}$ nas purinas microbianas (mg N/mol); 0,134 = relação $\mathrm{N}$ purinas: $\mathrm{N}$ total nas bactérias; e $0,83=$ digestibilidade das purinas bacterianas.
$\mathrm{O}$ balanço dos compostos nitrogenados $(\mathrm{BN})$ foi obtido pela diferença entre o total de $\mathrm{N}$ ingerido e o total de $\mathrm{N}$ excretado nas fezes e na urina. A eficiência microbiana foi expressa através de gramas de proteína bruta microbiana/kg de nutrientes digestíveis totais (g PBmic/kg NDT).

A análise estatística foi realizada com auxílio do programa estatístico SAS (Versão 9,2). Os dados foram analisados por análise de regressão com nível de significância de 5\%. Alguns dados tiveram que ser transformados para obedecerem as premissas de normalidade. Os dados são expressos com base nos dados originais. Por isso, para as variáveis CMSF, FDNI, CMSFR, CMOPR utilizou-se a transformação LOG10 e para a variável DMST utilizou-se a transformação elevado a 2, para que as mesmas pudessem ser analisadas corretamente. Entretanto, para a elaboração das tabelas utilizou-se somente os dados originais (sem transformação).

\section{Resultados e Discussão}

A massa de forragem (MF), matéria seca potencialmente digestível (MSpD) e os componentes da planta: lâmina foliar seca, pseudocolmo verde e pseudocolmo seco reduziram com o avançar dos períodos experimentais (Figura 1). No entanto, a massa de lâmina foliar verde reduziu do primeiro para o terceiro período e aumentou no quarto e quinto período, como resultado de condições climáticas favoráveis (Tabela 1). Assim, a MF apresentou aumento de 4,7 vezes. 
Figura 1. Valores médios de massa de forragem (MF), disponibilidades de MS potencialmente digestível (MSpD), MS de lâmina foliar verde (MLFV), MS de lâmina foliar seca (MLFS), MS de pseudocolmo verde (MPCV) e MS de pseudocolmo seco (MPCS) de Brachiaria brizantha cv. Marandu nos períodos experimentais.

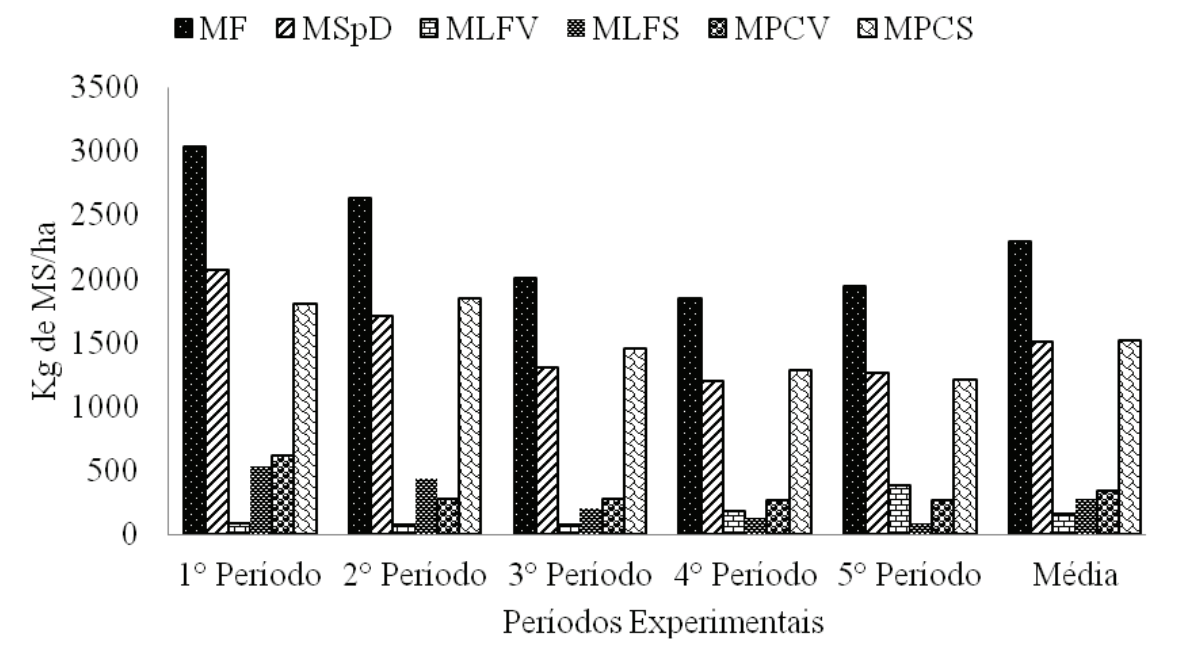

Fonte: Elaboração dos autores.

Apesar da baixa relação lamina valor pode ser justificado pela ocorrência de chuvas foliar:pseudocolmo $(0,23)$ observada na forragem, no período, que proporcionou durante os períodos a amostra de pasto obtida via simulação manual de experimentais, aumento na matéria seca de lâmina pastejo apresentou elevada quantidade de proteína foliar verde (Figuras 1 e 2), contribuindo assim para bruta (PB) de 78,40g/kg de MS (Tabela 3). Este o aumento no valor da quantidade de PB.

Tabela 3. Composição nutricional dos suplementos e da forragem.

\begin{tabular}{|c|c|c|c|c|c|}
\hline \multirow{2}{*}{ Item } & \multicolumn{4}{|c|}{ Suplemento $^{1}$} & \multirow{2}{*}{ Forragem } \\
\hline & 2 & 4 & 6 & 8 & \\
\hline Matéria seca ${ }^{2}$ & 862,5 & 878,4 & 886,7 & 890,7 & 400,6 \\
\hline Matéria orgânica ${ }^{3}$ & 955,0 & 952,8 & 950,9 & 951,0 & 912,8 \\
\hline Matéria mineral $^{3}$ & 45,0 & 47,2 & 49,1 & 49,0 & 87,1 \\
\hline Proteína bruta ${ }^{3}$ & 340,3 & 294,5 & 282,0 & 268,8 & 78,4 \\
\hline Extrato etéreo $^{3}$ & 22,7 & 23,7 & 23,8 & 24,3 & 25,9 \\
\hline Carboidratos totais ${ }^{3}$ & 616,2 & 641,7 & 649,9 & 661,6 & 801,3 \\
\hline Fibra em detergente neutro $(\mathrm{FDN})^{3}$ & 343,5 & 355,0 & 371,6 & 376,0 & 678,5 \\
\hline Fibra em detergente ácido ${ }^{3}$ & 238,9 & 245,8 & 258,9 & 262,2 & 401,4 \\
\hline FDN corrigida para cinza e proteína ${ }^{3}$ & 304,1 & 315,2 & 329,2 & 332,4 & 638,0 \\
\hline FDN indigestível ${ }^{3}$ & 63,0 & 64,5 & 65,8 & 67,3 & 178,3 \\
\hline Nitrogênio insolúvel em detergente neutro ${ }^{4}$ & 281,9 & 284,5 & 300,3 & 310,3 & 489,0 \\
\hline Nitrogênio insolúvel em detergente ácido ${ }^{4}$ & 92,1 & 93,2 & 98,6 & 101,8 & 395,8 \\
\hline Carboidratos não fibrosos ${ }^{3}$ & 283,9 & 298,2 & 290,4 & 297,9 & 163,3 \\
\hline Nutrientes digestíveis totais estimados ${ }^{3}$ & 433,8 & 456,1 & 454,3 & 461,1 & 496,8 \\
\hline
\end{tabular}

${ }^{1}$ Níveis de fornecimento de suplementos de 0,$55 ; 1,11 ; 1,66$ e 2,22\% do peso corporal para 2, 4, 6 e $8 \mathrm{~kg} /$ animal/dia, respectivamente; ${ }^{2}(\mathrm{~g} / \mathrm{kg}) ;{ }^{3}(\mathrm{~g} / \mathrm{kg}$ de matéria seca $) ;{ }^{4}(\mathrm{~g} / \mathrm{kg}$ de nitrogênio total);

Fonte: Elaboração dos autores. 
Figura 2. Proporção dos componentes estruturais (MS de lâmina foliar verde (MLFV) MS de lâmina foliar seca (MLFS), MS de pseudocolmo verde (MPCV), MS de pseudocolmo seco (MPCS)) da massa de forragem da pastagem de Brachiaria brizantha, cv. Marandu durante os períodos experimentais.

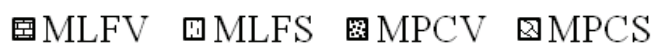

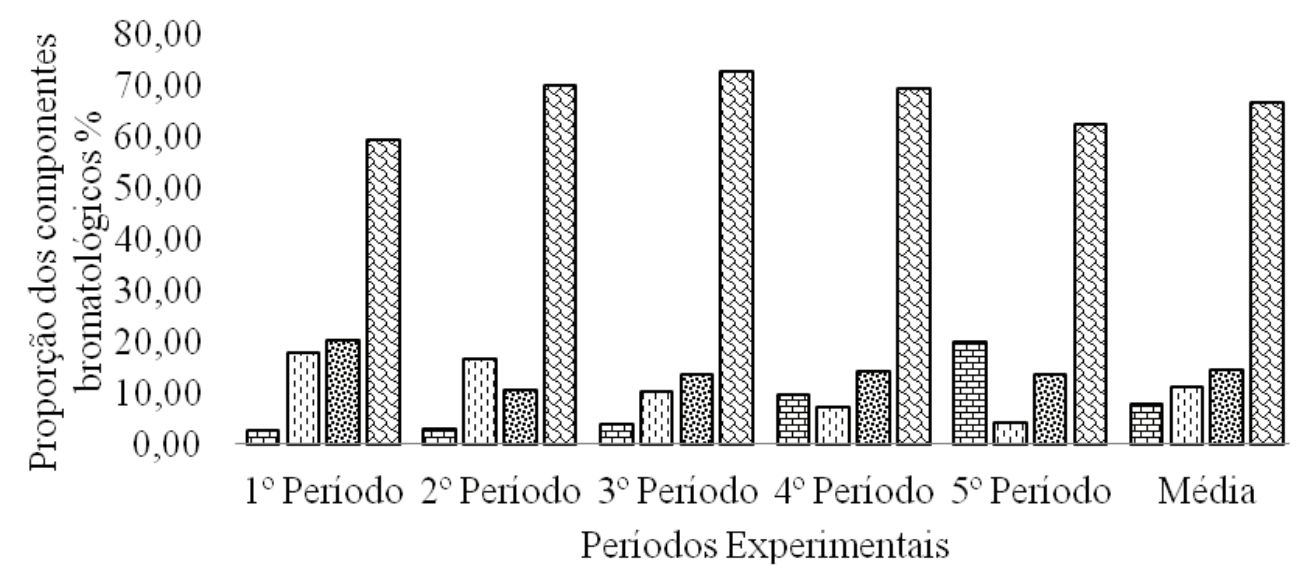

Fonte: Elaboração dos autores.

A concentração de PB na forragem (Tabela 3) foi superior ao mínimo necessário para permitir adequado crescimento microbiano e degradação da fibra. Quando a concentração de PB da dieta é menor do que $7 \%$, o consumo de forragem reduz, em virtude da deficiência de nitrogênio na forma de amônia para as bactérias fibrolíticas (VAN SOEST, 1994). Além disso, não atende às exigências microbianas em compostos nitrogenados e não permite adequada fermentação dos carboidratos fibrosos no rúmen (LAZZARINI et al., 2009).

As estratégias de suplementação promoveram incrementos sobre os consumos de matéria seca (CMS), matéria orgânica (CMO), proteína bruta (CPB), carboidratos não fibrosos (CCNF) e nutrientes digestíveis totais (CNDT), ou seja, apresentaram aumento linear $(\mathrm{P}<0,0001)$ em função do fornecimento de suplementos (Tabela 4).

Os consumos dos animais que receberam suplementos múltiplos, expressos em $\mathrm{kg} / \mathrm{animal} / \mathrm{dia}$ ou $\mathrm{g} / \mathrm{kg}$ de $\mathrm{PC}$, foram superiores aos daqueles que consumiram apenas mistura mineral, no entanto, o fornecimento de suplemento aos animais afetou o consumo de matéria seca de forragem (CFO) em kg/animal/dia, ou seja, apresentou comportamento linear decrescente $(\mathrm{P}<0,0001)$ em função dos níveis de suplementação, indicando que houve efeito substitutivo.

Segundo Minson (1990), o consumo de forragem no período da seca é substituído pelo suplemento em no máximo 64\%. Além disso, o efeito substitutivo ocorre quando se fornece suplementos em quantidade superior a $0,2 \%$ do PC (HERD, 1997). Deste modo, o menor consumo de forragem ocasionado pelo alto fornecimento de suplemento tem significativa importância em sistemas de pastejo de não equilíbrio, pois essas estratégias buscam a maximização da digestão ruminal, consumo e desempenho animal em sistemas de produção de bovinos com pouca oferta de forragem.

A suplementação múltipla tende a substituir o consumo de forragem em pastagens de baixa qualidade, mas isso não prejudica o desempenho dos animais (DEL CURTO et al., 1990). A redução no desempenho pode ser mais pronunciada em maiores níveis de suplementação, sobretudo naqueles com elevados teores de carboidratos não-fibrosos (CNF) de rápida fermentação (DIXON; STOCKDALE, 1999) 
Tabela 4. Valores médios de consumos de matéria seca (CMS), matéria seca de forragem (CFO), matéria orgânica total $(\mathrm{CMO})$, proteína bruta $(\mathrm{CPB})$, extrato etéreo (CEE), fibra em detergente neutro (CFDN), fibra em detergente neutro indigestível (CFDNi), carboidratos totais (CCT), carboidratos não fibrosos (CCNF) e Nutrientes Digestíveis Totais (CNDT) em novilhas no período da seca.

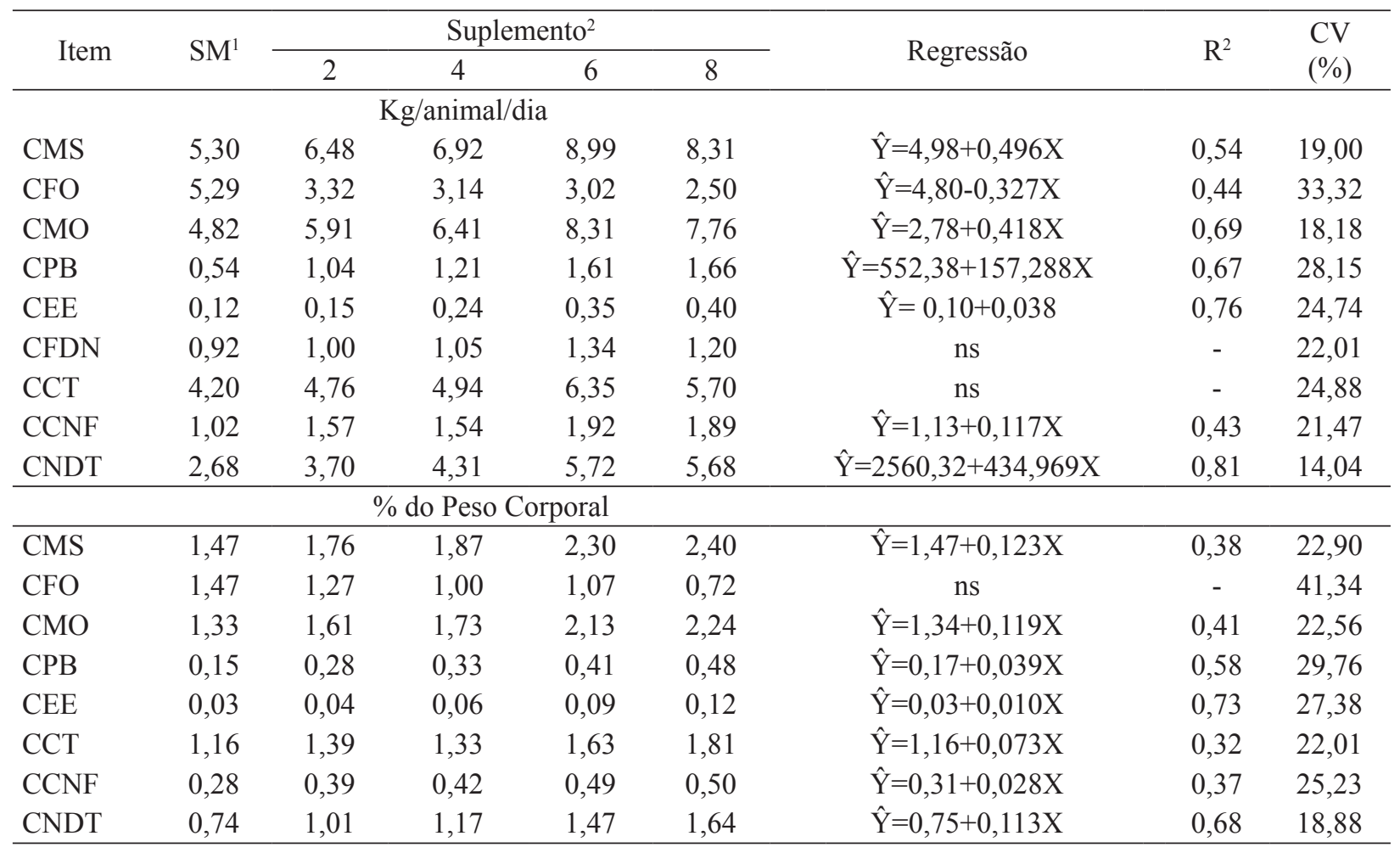

${ }^{1}$ Suplemento mineral comercial; ${ }^{2}$ Níveis de fornecimento de suplementos de 0,$55 ; 1,11 ; 1,66$ e 2,22\% do peso corporal para 2,4 , 6 e $8 \mathrm{~kg} /$ animal $/$ dia, respectivamente.

Fonte: Elaboração dos autores.

Os suplementos promoveram mudanças no coeficiente de digestibilidade aparente total da MS, MO, FDN, CT e CNF (Tabela 5), ou seja, à medida que foi aumentando a quantidade ofertada de suplemento, a digestibilidade dos nutrientes aumentou linearmente $(\mathrm{P}<0,0001)$, o que comprova que o fornecimento de suplemento para bovinos em pastejo potencializa a digestão dos nutrientes da forragem.

Resultados semelhantes em relação à melhoria da digestibilidade da matéria seca total com a suplementação foram verificados por diversos autores (PORTO et al., 2011; BARONI et al., 2010; ACEDO et al., 2007; MORAES et al., 2009) que utilizaram suplementos de elevado consumo $(0,25$ a
$4 \mathrm{~kg} /$ animal/dia), o que permitiu um incremento de nutrientes de maior digestibilidade.

A digestibilidade total da proteína foi maior para os animais suplementados em comparação ao controle. Essa ampliação da digestibilidade está relacionada ao maior aporte de nitrogênio fornecido pelos suplementos (Tabela 3). Resultados semelhantes foram relatados por Valadares et al. (1997) que verificaram aumento na digestibilidade aparente da proteína com o aumento no consumo de proteína bruta na dieta e atribuíram essa resposta à diminuição da proporção de nitrogênio endógeno nos compostos nitrogenados fecais com o aumento na ingestão de nitrogênio. 
Tabela 5. Valores médios de coeficientes de digestibilidade aparente total (\%) da matéria seca (DMS), matéria seca de forragem (DFO), proteína bruta (DPB), fibra em detergente neutro (DFDN), carboidratos totais (DCT) e carboidratos não fibrosos (DCNF) em novilhas no período da seca.

\begin{tabular}{|c|c|c|c|c|c|c|c|c|}
\hline \multirow{2}{*}{ Variáveis } & \multirow{2}{*}{$\mathrm{SM}^{1}$} & \multicolumn{4}{|c|}{ Suplemento $^{2}$} & \multirow{2}{*}{ Regressão } & \multirow{2}{*}{$\mathrm{R}^{2}$} & \multirow{2}{*}{$\mathrm{CV}(\%)$} \\
\hline & & 2 & 4 & 6 & 8 & & & \\
\hline DMS & 45,36 & 55,57 & 60,04 & 69,31 & 66,87 & $\hat{\mathrm{Y}}=2428,58+325,287 \mathrm{X}$ & 0,42 & 29,67 \\
\hline DFO & 50,34 & 59,78 & 63,87 & 70,12 & 69,95 & $\hat{Y}=52,61+2,623 X$ & 0,39 & 14,69 \\
\hline DPB & 51,33 & 70,28 & 74,28 & 74,50 & 74,85 & $\hat{Y}=53,69+8,245 X-0,732 X^{2}$ & 0,59 & 32,84 \\
\hline DFDN & 68,82 & 74,96 & 79,79 & 83,51 & 83,16 & $\hat{Y}=70,35+1,984 X$ & 0,40 & 8,72 \\
\hline DCT & 51,10 & 57,72 & 61,60 & 68,02 & 67,27 & $\hat{Y}=52,36+2,257 \mathrm{X}$ & 0,31 & 15,48 \\
\hline DCNF & 46,60 & 52,84 & 54,89 & 62,31 & 63,27 & $\hat{Y}=36,21+4,178 X$ & 0,35 & 30,75 \\
\hline
\end{tabular}

${ }^{1}$ Suplemento mineral comercial; ${ }^{2}$ Níveis de fornecimento de suplementos de 0,$55 ; 1,11 ; 1,66$ e $2,22 \%$ do peso corporal para 2 , 4 , 6 e $8 \mathrm{~kg} /$ animal/dia, respectivamente.

Fonte: Elaboração dos autores.

Os valores encontrados para digestibilidade da FDN (DFDN) foram de 68,82 e 80,35\% e para DCT foram de 51,10 e 63,65\%, respectivamente, para o suplemento mineral e suplementos múltiplos. $\mathrm{O}$ que pode ter contribuído para esta diferença foi o maior aporte de nitrogênio e energia, devido à suplementação múltipla, suprindo a deficiência dos microrganismos ruminais e, como consequência, incrementando de forma positiva a atividade das bactérias celulolíticas ruminais.

O valor de $46,60 \%$ de digestibilidade dos carboidratos não-fibrosos (DCNF) nos animais recebendo apenas suplemento mineral está associado à não participação de concentrado na dieta, visto que, a adição de grãos ricos em amido à dieta, que possuem teores maiores de carboidratos não estruturais permite maior consumo (Tabela 4) e maior digestibilidade (Tabela 5) em comparação às dietas ricas em carboidratos estruturais, que são menos digestíveis.

Os efeitos positivos no consumo de MST, MO, $\mathrm{PB}, \mathrm{EE}, \mathrm{CNF}$ e NDT e digestibilidade da MST, MO, PB, FDN, CT e CNF em animais suplementados foram decorrentes do maior aporte nutricional de nitrogênio e energia fornecidos pelos suplementos suprindo as exigências dos microrganismos ruminais.
As estratégias de suplementação promoveram redução do $\mathrm{pH}$ ruminal no tempo zero hora (antes do fornecimento de suplemento), ou seja, apresentou comportamento linear decrescente $(\mathrm{P}=0,0343) \mathrm{em}$ função dos níveis de fornecimento de suplementos (Tabela 6). Já no tempo de duas horas após suplementação, o fornecimento de suplementos não influenciou os valores de $\mathrm{pH}$ ruminal (Tabela 6). Este comportamento pode ser explicado pelo horário de coleta ter sido realizado as 17:00 horas, ou seja, o tempo de duas horas não foi suficiente em promover uma adequada fermentação ruminal e consequente redução no $\mathrm{pH}$. Possivelmente houve redução em tempos maiores após a suplementação, ou seja, após as 18:00 horas. Além disso, deve-se considerar que a suplementação da manhã (10:00 horas) não influenciou os valores de $\mathrm{pH}$, pois este reduziria de 4 a 6 horas após a suplementação, correspondendo respectivamente as 14 e 16 horas. Isso pode justificar a inalteração observada após a suplementação.

Os valores médios observados para o $\mathrm{pH}$ ruminal estiveram entre 6,44 e 6,78 antes da suplementação da manhã e entre 6,43 a 6,79, duas horas após o fornecimento de suplemento da tarde (Tabela 6). Esses valores sempre se mantiveram superiores a 6,0 , visto que, quando o $\mathrm{pH}$ encontra-se abaixo deste valor, verifica-se redução de forma acentuada 
na digestão da fibra devido a diminuição na população de microrganismos celulolíticos. Estas bactérias são sensíveis em $\mathrm{pH}$ abaixo deste valor, podendo chegar a severa inibição em $\mathrm{pH}$ de 4,5 a 5,0 , considerando que a faixa adequada para essas bactérias seriam próximos de 6,7 (VAN SOEST, 1994).

Tabela 6. Valores médios de pH e concentração de nitrogênio amoniacal $\left(\mathrm{N}_{-} \mathrm{NH}_{3}\right)(\mathrm{mg} / \mathrm{dL})$, no liquido ruminal de novilhas nelores submetidos a cinco dietas experimentais, nos diferentes tempos de amostragem: antes da alimentação e 2 horas após alimentação em dois dias consecutivos.

\begin{tabular}{|c|c|c|c|c|c|c|c|c|c|}
\hline \multirow{2}{*}{ Item } & \multirow{2}{*}{ Tempo } & \multirow{2}{*}{$\mathrm{SM}^{1}$} & \multicolumn{4}{|c|}{ Suplementos } & \multirow{2}{*}{ Regressão } & \multirow{2}{*}{$\mathrm{R}^{2}$} & \multirow{2}{*}{$\begin{array}{l}\mathrm{CV} \\
(\%)\end{array}$} \\
\hline & & & 2 & 4 & 6 & 8 & & & \\
\hline \multirow{2}{*}{$\mathrm{pH}$} & $0 \mathrm{~h}$ & 6,78 & 6,75 & 6,76 & 6,59 & 6,44 & $\hat{\mathrm{Y}}=6,83-0,042 \mathrm{X}$ & 0,18 & 3,76 \\
\hline & $2 \mathrm{~h}$ & 6,75 & 6,79 & 6,72 & 6,61 & 6,43 & ns & - & 4,48 \\
\hline \multirow{2}{*}{ N-NH3 } & $\mathrm{Oh}$ & 5,09 & 7,26 & 7,45 & 9,10 & 7,52 & $\hat{\mathrm{Y}}=0,71+0,028 \mathrm{X}$ & 0,15 & 23,57 \\
\hline & $2 \mathrm{~h}$ & 5,90 & 14,15 & 18,31 & 19,27 & 11,80 & $\hat{Y}=0,71+0,242 X-0,026 X^{2}$ & 0,49 & 19,94 \\
\hline
\end{tabular}

${ }^{1}$ Suplemento mineral comercial; ${ }^{2}$ Níveis de fornecimento de suplementos de 0,$55 ; 1,11 ; 1,66$ e 2,22\% do peso corporal para 2,4 , 6 e $8 \mathrm{~kg} /$ animal/dia, respectivamente.

Fonte: Elaboração dos autores.

A concentração de nitrogênio amoniacal ruminal $\left(\mathrm{N}-\mathrm{NH}_{3}\right)$ apresentou no tempo zero hora, comportamento linear crescente $(\mathrm{P}=0,0004)$ e no tempo duas horas, comportamento quadrático $(\mathrm{P}=0,0023)$ em função dos níveis de suplementação (Tabela 6).

Os valores observados de $\mathrm{N}-\mathrm{NH}_{3}$, quando os animais receberam apenas suplementação mineral em ambos os tempos e suplementação no tempo zero, foram inferiores a $10,0 \mathrm{mg} / \mathrm{dL}$, valor este considerado por Leng (1990) e Lazzarini et al. (2009) como adequado à fermentação ruminal em animais mantidos em condições tropicais. No entanto, apenas os animais que receberam suplementos múltiplos apresentaram, duas horas após o fornecimento, concentração de $\mathrm{N}_{-} \mathrm{NH}_{3}$ dentro da faixa ideal (10 a $20 \mathrm{mg} / \mathrm{dL})$ para garantir o máximo crescimento microbiano e maior eficiência de utilização da energia oriunda da degradação dos carboidratos em condições tropicais (LENG, 1990).

$\mathrm{O}$ efeito quadrático da quantidade de nitrogênio amoniacal após o fornecimento de suplemento e o efeito linear crescente observado para o coeficiente de digestibilidade total da proteína bruta indicam que o aumento nos níveis de suplementação acarretou em maior aporte de nitrogênio ruminal e pode ter ocasionado em maior escape de nitrogênio no rúmen até o fornecimento de $6 \mathrm{~kg}$ de suplemento.

$\mathrm{O}$ comportamento dos dados de $\mathrm{N}_{-} \mathrm{NH}_{3}$ pode ser explicado pela redução no $\mathrm{pH}$ ruminal, e consequentemente, diminuição dos microrganismos ruminais promovidos pelos maiores níveis de suplementação, os quais teriam levado a uma menor proteólise ruminal. No entanto, essa redução $\mathrm{N}-\mathrm{NH}_{3}$ não foi acompanhada de diminuição do $\mathrm{pH}$, visto que, isto pode ser decorrente da coleta de amostras de líquido ruminal realizada por sonda esofágica, a qual possivelmente tenha coletado fluido ruminal proveniente da porção cranial do retículorúmen. Sendo assim, esses valores de $\mathrm{pH}$ não são representativos, tendo em vista que, o líquido não foi coletado na região de interface líquido/sólido do ambiente ruminal, e essas amostras poderiam estar contaminadas com saliva.

Os níveis de suplementação não influenciaram a produção de proteína microbiana e a eficiência de síntese microbiana (Tabela 7). 
Tabela 7. Valores médios de nitrogênio ingerido (NI), volume urinário (VU), nitrogênio uréico no soro (NUS), excreção de ureia na urina (UEU), excreção de nitrogênio na urina (NEU), excreção de nitrogênio nas fezes (NEF), nitrogênio absorvido (NAbs), balanço de nitrogênio (BN), nitrogênio microbiano (Nmic), proteína microbiana (Pmic) e eficiência microbiana (Emic) em função dos suplementos.

\begin{tabular}{|c|c|c|c|c|c|c|c|c|}
\hline \multirow{2}{*}{ Item } & \multirow{2}{*}{$\mathrm{SM}^{1}$} & \multicolumn{4}{|c|}{ Suplemento $^{2}$} & \multirow{2}{*}{ Regressão } & \multirow{2}{*}{$\mathrm{R}^{2}$} & \multirow{2}{*}{$\mathrm{CV}(\%)$} \\
\hline & & 2 & 4 & 6 & 8 & & & \\
\hline $\mathrm{NI}^{3}$ & 86,16 & 166,03 & 193,67 & 258,03 & 269,03 & $\hat{Y}=103,03+22,886 X$ & 0,61 & 26,94 \\
\hline $\mathrm{VU}^{4}$ & 17,91 & 14,62 & 13,26 & 13,33 & 11,56 & - & & \\
\hline NUS $^{5}$ & 23,28 & 46,40 & 47,92 & 60,28 & 49,48 & - & & \\
\hline $\mathrm{UEU}^{3}$ & 72,00 & 212,65 & 203,67 & 268,98 & 221,29 & $\hat{Y}=10,28+0,750 X$ & 0,23 & 29,48 \\
\hline $\mathrm{NEU}^{3}$ & 33,55 & 99,10 & 86,66 & 125,08 & 103,12 & $\hat{Y}=5,79+1,709 X-0,148 X^{2}$ & 0,42 & 23,51 \\
\hline $\mathrm{NEF}^{3}$ & 35,77 & 45,71 & 55,33 & 64,79 & 65,35 & $\hat{\mathrm{Y}}=37,74+3,912 \mathrm{X}$ & 0,56 & 18,80 \\
\hline $\mathrm{NAbs}^{3}$ & 50,39 & 120,32 & 138,34 & 193,24 & 203,68 & - & & \\
\hline $\mathrm{BN}^{3}$ & 16,84 & 21,22 & 51,68 & 68,16 & 100,56 & - & & \\
\hline $\mathrm{Nmic}^{6}$ & 28,36 & 25,77 & 23,63 & 22,89 & 24,12 & - & & \\
\hline $\mathrm{Pmic}^{3}$ & 177,26 & 161,06 & 147,71 & 143,08 & 150,78 & ns & & \\
\hline Emic $^{7}$ & 70,86 & 90,43 & 99,00 & 126,57 & 119,50 & ns & & \\
\hline
\end{tabular}

${ }^{1}$ Suplemento mineral comercial; ${ }^{2}$ Níveis de fornecimento de suplementos de 0,$55 ; 1,11 ; 1,66$ e 2,22\% do peso corporal para $2,4,6$ e $8 \mathrm{~kg} / \mathrm{animal} / \mathrm{dia}$, respectivamente; ${ }^{3}$ (g/dia); ${ }^{4}(\mathrm{~L} / \mathrm{dia}) ;{ }^{5}(\mathrm{mg} / \mathrm{dL}) ;{ }^{6}(\mathrm{~g}$ de N$/ \mathrm{dia}) ;{ }^{7}(\mathrm{~g}$ Pmic/ $\mathrm{kg}$ de NDT$)$

Fonte: Elaboração dos autores.

O valor médio de eficiência microbiana, verificado neste trabalho (15,07 g PB microbiana/100 $\mathrm{g}$ de NDT), mostrou-se superior ao verificado pelo NRC (2001) (13 g PB microbiana/ 100 g de NDT) e aos valores relatados em bovinos suplementados em pastagens em condições brasileiras (MORAES et al., 2009; ZERVOUDAKIS et al., 2010).

Segundo Verbic (2002) a proteína microbiana é a melhor fonte para atender os requerimentos de aminoácidos do animal, tendo em vista que, a mesma é semelhante à proteína dos tecidos animal quanto à composição aminoacídica. Deste modo, vale ressaltar a importância na utilização de estratégias de suplementação que potencialize a produção microbiana em sistemas de produção de bovinos com limitada oferta de pasto, pois aumentaria o fluxo de proteína de alto valor biológico para o intestino, maximizando seu desempenho animal.

O fornecimento de níveis crescentes de suplementos aumentaram linearmente $(\mathrm{P}<0,0001)$ a ingestão de nitrogênio (N) (Tabela 7), e consequentemente, a excreção de $\mathrm{N}$ nas fezes e de uréia na urina $(\mathrm{P}<0,0001)$. No entanto, quando realizado o balanço de nitrogênio, os animais suplementados apresentaram maior retenção de $\mathrm{N}$ (Tabela 7) e, à medida que se aumentou o nível de suplementação, aumentou a retenção de $\mathrm{N}$, comprovando que as maiores ofertas de suplemento proporcionaram uma relação energia:proteína mais favorável à retenção de $\mathrm{N}$.

$\mathrm{O}$ nitrogênio excretado na urina (NEU) apresentou comportamento quadrático $(\mathrm{P}=0,0491)$ em função dos níveis de fornecimento de suplemento. Este resultado acompanhou o comportamento quadrático da concentração de $\mathrm{N}_{-} \mathrm{NH}_{3}$, ou seja, o maior fornecimento de suplemento (8 kg) apresentou menor concentração de $\mathrm{N}-\mathrm{NH}_{3}$ e menor concentração de nitrogênio uréico no soro (NUS) e, consequentemente, menor excreção de $\mathrm{N}$ na urina.

$\mathrm{O}$ comportamento da concentração de $\mathrm{N}_{-} \mathrm{NH}_{3}$ ruminal juntamente com o NUS corrobora a afirmação de Russell et al. (1992) de que a produção excessiva de $\mathrm{N}_{-} \mathrm{NH}_{3}$ e sua consequente absorção ruminal aumentam a excreção urinária de nitrogênio. Além disso, a quantidade ou degradabilidade da proteína dietética afeta o metabolismo da ureia 
(HUNTINGTON; ARCHIBEQUE, 1999), fato evidenciado pelas alterações nas concentrações NUS e NEU.

\section{Conclusões}

A oferta de suplementos em níveis crescentes durante o período da seca resulta em aumento do consumo de matéria seca e redução do consumo de matéria seca de forragem. Essa estratégia de suplementação pode ser fornecida para bovinos durante o período da seca em situações de pouca oferta de pasto.

\section{Referências}

ACEDO, T. S.; PAULINO, M. F.; DETMANN, E.; VALADARES FILHO, S. C.; MORAES, E. H. B. K.; FIGUEIREDO, D. M. Níveis de uréia em suplementos para terminação de bovinos em pastejo durante a época seca. Acta Scientiarum Animal Science, Maringá, v. 29, n. 3, p. 301-308, 2007.

BARONI, C. E. S.; LANA, R. P.; MANCIO, A. B.; MENDONÇA, B. P. C.; LEÃO, M. I.; SVERZUT, C. B. Consumo e digestibilidade de nutrientes em novilhos suplementados e terminados em pasto, na seca. Arquivo Brasileiro de Medicina Veterinária e Zootecnia, Belo Horizonte, v. 62, n. 2, p. 365-372, 2010.

BURNS, J. C.; POND, K. R.; FISHER, D. S. Measurement of forage intake. In: FAHEY JUNIOR, G. C. Forage quality, evaluation and utilization. Madison: American Society of Agronomy, 1994. p. 494-531.

CASALI, A. O.; DETMANN, E.; VALADARES FILHO, S. C.; PEREIRA, J. C.; HENRIQUES, L. T.; FREITAS, S. G.; PAULINO, M. F. Influencia do tempo de incubação e do tamanho de partículas sobre os teores de compostos indigestíveis em alimentos e fezes bovinas obtidos por procedimento in situ. Revista Brasileira de Zootecnia, Viçosa, MG, v. 37, n. 2, p. 335-342, 2008.

CHEN, X. B.; GOMES, M. J. Estimation of microbial protein supply to sheep and cattle basid on urinary excretion of purine derivatives-an overview of the technical details. Aberdeen: International Feed Research Unit. Rowett Research Institute, Ocasional Publication, 1992. $21 \mathrm{p}$.

CHIZZOTTI, M. L.; VALADARES FILHO, S. C.; VALADARES, R. F. D.; CHIZZOTTI, F. H. M.;
TEDESCHI, L. O. Determination of creatinine excretion and evaluation of spot urine sampling in Holstein cattle. Livestock Science, Almsford, v. 113, n. 2, p. 218-225, 2008.

DEL CURTO, T.; COCHRAN, R. C.; CORAH, L. R.; BEHARKA, A. A.; ZANZANT, E. S.; JOHNSON, D. E. Supplementation of dormant Tallgrass-Prarie forage: II. Performance and forage utilization characteristics in grazing beef cattle receiving supplements of different protein concentrations. Journal of Animal Science, Champaign, v. 68, n. 2, p. 532-542, 1990.

DETMANN, E.; PAULINO, M. F.; ZERVOUDAKIS, J. T.; VALADARES FILHO, S. C.; EUCLYDES, R. F.; LANA, R. P.; QUEIROZ, D. S. Cromo e indicadores internos na estimação do consumo de novilhos mestiços, suplementados, a pasto. Revista Brasileira de Zootecnia, Viçosa, v. 30, n. 5, p. 1600-1609, 2001.

DIXON, R. M.; STOCKDALE, C. R. Associative effects between forages and grains: consequences for feed utilization. Australian Journal of Agricultural Research, Victoria, v. 50, n. 3, p. 757-773, 1999.

FUJIHARA, T.; ØRSKOV, E. R.; REEDS, P. J.; KYLE, D. J. The effect of protein infusion on urinary excretion of purine derivatives in ruminants nourished by intragastric nutrition. The Journal of Agricultural Science, Cambridge, v. 109, n. 1, p. 7-12, 1987.

HALL, M. B. Calculation of non-structural carbohydrate content of feeds that contain non-protein nitrogen. Gainesville: University of Florida, 2000. p. A-25 (Bulletin, 339).

HERD, D. B. Mineral supplementation of beef cows in Texas. Texas agricultural extension service B-6056. Texas: The Texas A\&M University System, 1997. 12 p.

HUNTINGTON, G. B.; ARCHIBEQUE, S. L. Practical aspects of urea and ammonia metabolism in ruminants. Journal of Animal Science, Cambridge, v. 77, p. 1-11, 1999.

LAZZARINI, I.; DETMANN, E.; SAMPAIO, C. B.; PAULINO, M. F.; VALADARES FILHO, S. C.; SOUZA, M. A.; OLIVEIRA, F. A. Intake and digestibility in cattle fed low quality tropical forage and supplemented with nitrogenous compounds. Revista Brasileira de Zootecnia, Viçosa, v. 38, n. 10, p. 2021-2030, 2009.

LENG, R. A. Factors affecting the utilization of "poorquality" forages by ruminants particularly under tropical conditions. Nutrition Research Review, Cambridge, v. 3, n. 3, p. 277-303, 1990.

MINSON, D. J. Forage in ruminant nutrition. New York: Academic Press, 1990. 483 p. 
MORAES, E. H. B. K.; PAULINO, M. F.; MORAES, K. A. K.; VALADARES FILHO, S. C.; ZERVOUDAKIS, J. T.; DETMANN, E. Ureia em suplementos proteicoenergéticos para bovinos de corte durante o período da seca: características nutricionais e ruminais. Revista Brasileira de Zootecnia, Viçosa, v. 38, n. 4, p. 770-777, 2009.

MORAES, E. H. B. K.; PAULINO, M. F.; ZERVOUDAKIS, J. T.; VALADARES FILHO, S. C.; CABRAL, L. S.; DETMANN, E.; VALADARES, R. F. D.; MORAES, K. A. K. Associação de diferentes fontes energéticas e protéicas em suplementos múltiplos na recria de novilhos mestiços sob pastejo no período da seca. Revista Brasileira de Zootecnia, Viçosa, v. 35, n. 3, p. 914-920, 2006.

NATIONAL RESEARCH COUNCIL - NRC. Nutrients requirements of dairy cattle. 7. ed. Washington: National Academy Press, 2001. 381 p.

PAULINO, M. F.; DETMANN, E.; VALADARES FILHO, S. C. Bovinocultura funcional nos trópicos. In: SIMPÓSIO INTERNACIONAL DE PRODUÇÃO DE GADO DE CORTE, 2., 2008, Viçosa, MG. Anais.... Viçosa, MG: SIMCORTE, 2008. v. 6, p. 275-305.

PAULINO, M. F.; DETMANN, E.; VALADARES FILHO, S. C. Suplementação animal em pasto: energética ou protéica? In: SIMPÓSIO SOBRE MANEJO ESTRATÉGICO DA PASTAGEM, 3., 2006, Viçosa, MG. Anais... Viçosa, MG: SIMFOR, 2006. p. 359-392.

PAULINO, M. F.; FIGUEIREDO, D. M.; MORAES, E. H. B. K.; PORTO, M. O.; SALES, M. F. L.; ACEDO, T. S.; VILLELA, S. D. J.; VALADARES FILHO, S. C. Suplementação de bovinos em pastagens: uma visão sistêmica. In: SIMPÓSIO DE PRODUÇÃO DE GADO DE CORTE, 4., 2004, Viçosa, MG. Anais... Viçosa, MG: SIMCORTE, 2004. p. 93-144.

PORTO, M. O.; PAULINO, M. F.; DETMANN, E.; VALADERES FILHO, S. C.; SALES, M. F. L.; CAVALI, J.; NASCIMENTO, M. L.; ACEDO, T. S. Ofertas de suplementos múltiplos para tourinhos Nelore na fase de recria em pastagens durante o período da seca: desempenho produtivo e características nutricionais. Revista Brasileira de Zootecnia, Viçosa, v. 40, n. 11, p. 2548-2557, 2011.

PRESTON, T. R. Biological and chemical analytical methods. In: PRESTON, T. R. (Ed.). Tropical animal feeding: a manual for research workers. Roma: FAO, 1995. p. 191-264.

REIS, R. A.; MELO, G. M. P; BERTIGAGLIA, L. M. A.; OliveIRA, A. P.; BALSAlOBRE, M. A. A. Suplementação de animais em pastagens: quantificação e custos. In: SIMPÓSIO SOBRE MANEJO DA
PASTAGEM, 22., 2005, Piracicaba. Anais... Piracicaba: Fundação de Estudos Agrários Luiz de Queiroz, 2005. v. 1, p. 279-352.

RUSSELL, J. B.; O'CONNOR, J. D.; FOX, D. G.; VAN SOEST, P. J.; SNIFFEN, C. J. A net carbohydrate and protein system for evaluation cattle diets: ruminal fermentation. Journal of Animal Science, Cambridge, v. 70, n. 12, p. 3551-3581, 1992.

SILVA, D. J.; QUEIROZ, A. C. Análise de alimentos: métodos químicos e biológicos. 3. ed. Viçosa: UFV, 2002. $235 \mathrm{p}$.

SNIFFEN, C. J.; O’CONNOR, J. D.; VAN SOEST, P. J.; FOX, D. G.; RUSSELL, J. B. A net carbohydrate and protein system for evaluating cattle diets: II. Carbohydrate and protein availability. Journal of Animal Science, Cambridge, v. 70, n. 12, p. 3562-3577, 1992.

VALADARES FILHO, S. C.; PAULINO, P. V. R.; MAGALHÃES, K. A. Exigências nutricionais de zebuínos e tabelas de composição de alimentos (BRCORTE). Visconde do Rio Branco: Suprema Gráfica Ltda, 2006. v. 1, 142 p.

VALADARES, R. F. D.; BRODERICK, G. A.; VALADARES FILHO, S. C.; CLAYTON, M. K. Effect of replacing alfalfa silage with high moisture corn on ruminal protein synthesis estimated from excretion of total purine derivatives. Journal of Dairy Science, Cambridge, v. 82, n. 11, p. 2686-2696, 1999.

VALADARES, R. F. D.; GONÇALVES, L. C.; RODRIGUEZ. N. M.; VALADRES FILHO, C. C.; SAMPAIO, I. B. M. Níveis de proteína bruta em dietas de bovinos. 4. Concentração de amônia ruminal, uréia plasmática e excreções de creatinina. Revista Brasileira de Zootecnia, Viçosa, v. 26, n. 6, p. 1270-1278, 1997.

VAN SOEST, P. J. Nutritional ecology of the ruminant. 2. ed. Ithaca: Cornell University, 1994. 476 p.

VAN SOEST, P. J.; ROBERTSON, J. B.; LEWIS, B. A. Symposium: carboydrate metodology, metabolism, and nutritional implications in dairy cattle. Journal Dairy Science, Cambridge, v. 74, n. 10, p. 3583-3597, 1991.

VERBIC, J. Factors affecting microbial protein synthesis in the rumen with emphasis on diets containing forages. Gumpenstein, Germany: Viehwirtschaftliche Fachtagung, Milchproduktion und Rindermast. Gumpenstein, 2002. $10 \mathrm{p}$.

VERBIC, J.; CHEN, X. B.; MACLEOD, N. A.; ØRSKOV, E. R. Excretion of purine derivatives by ruminants. Effect of microbial nucleic acid infusion on purine derivative excretion by steers. Journal of Agricultural Science, Cambridge, v. 114, n. 3, p. 243-248, 1990. 
ZERVOUDAKIS, J. T.; PAULINO, M. F.; CABRAL, L.; DETMANN, E.; VALADARES FILHO, S. C.; MORAES, E. H. B. K. Parâmetros nutricionais de novilhos sob suplementação em sistema de autocontrole de consumo no período de transição águas-seca. Revista Brasileira de Zootecnia, Viçosa, v. 39, n. 12, p. 27532762, 2010.
ZERVOUDAKIS, J. T.; SILVA, L. C. R. P.; SILVA, R. P.; JOSÉ NETO, A.; WERNER, J. F. K.; SILVA, R. G. F. Otimização do desempenho de bovinos por meio da suplementação à pasto. In: SIMPÓSIO MATOGROSSENSE DE BOVINOCULTURA DE CORTE, 1., 2011, Cuiabá. Anais... Cuiabá: I SIMBOVMT, 2011. v. 1, p. 151-189. 